\title{
Lymphedema in women undergoing breast cancer surgery
}

\author{
Linfedema em mulheres submetidas à cirurgia por câncer de mama
}

Priscila Lara Vieira Bonisson ${ }^{1}$, Mei Rosemary Fu², Selme Silqueira de Matos ${ }^{1}$, Giovana Paula Rezende Simino ${ }^{1}$, Elenice Ribeiro de Paula Lima ${ }^{1}$, Flávia Falci Ercole ${ }^{1}$

Objective: to estimate the prevalence and to identify possible factors associated with the occurrence of lymphedema in women undergoing treatment for breast cancer. Methods: a prevalence study with 125 women. An interview and a consultation of the medical record were carried out using a questionnaire. Univariate and multivariate analysis were performed through logistic regression. Results: a prevalence rate of $34.4 \%$ was found. Obesity, sentinel lymph node biopsy, radiotherapy, and the presence of some treatment complications were statistically significant for the occurrence of lymphedema. Conclusion: the prevalence of lymphedema in this study was high. The variables positively related to lymphedema, considered as associated factors, were: obesity, sentinel lymph node biopsy, radiotherapy and some treatment related complications (adhesion, retraction, paraesthesia, seroma, fibrosis, infection and dehiscence).

Descriptors: Breast Neoplasms; Mastectomy; Lymphedema; Lymph Node Excision; Nursing.

Objetivo: estimar a prevalência e identificar possíveis fatores associados à ocorrência do linfedema em mulheres submetidas a tratamento para câncer de mama. Métodos: estudo de prevalência, com 125 mulheres. Foi realizada entrevista e consulta ao prontuário utilizando-se de questionário. Realizou-se análise univariada e multivariada por meio da regressão logística. Resultados: encontrou-se uma taxa de prevalência de 34,4\%. A obesidade, a biópsia de linfonodo sentinela, a radioterapia e a presença de alguma complicação do tratamento mostraram-se estatisticamente significativos para a ocorrência do linfedema. Conclusão: a prevalência de linfedema neste estudo foi alta. As variáveis positivamente relacionadas ao linfedema, consideradas como fatores associados, foram: obesidade, biópsia de linfonodo sentinela, radioterapia e ter alguma complicação relacionada ao tratamento (aderência, retração, parestesia, seroma, fibrose, infecção e deiscência).

Descritores: Neoplasias da Mama; Mastectomia; Linfedema; Excisão de Linfonodo; Enfermagem.

\footnotetext{
${ }^{1}$ Universidade Federal De Minas Gerais. Belo Horizonte, MG, Brazil.

${ }^{2}$ University of Nova York. Nova York, USA. 


\section{Introduction}

Breast cancer is the most frequent and the leading cause of cancer death among women in Brazil. The number of new cancer cases for all Brazilian states and their capitals for the years 2016 and 2017 was estimated at 58,000 new cases of breast cancer in Brazil and 5,160 new cases in Minas Gerais ${ }^{(1)}$.

Among breast cancer treatments, surgery is still considered the first choice for breast cancer. Depending on the clinical and pathological characteristics of the tumor, surgery involves the resection of axillary lymph nodes and the rupture of lymphatic pathways, which compromises lymphatic drainage of the region and causes accumulation of fluid over time, causing lymphedema ${ }^{(2)}$.

Lymphedema, characterized by enlargement of the upper limb due to accumulation of lymph in the interstitium, is a serious morbidity which, if not prevented or treated properly, results in significant impairment of the affected limb. Lymphedema also implies limitation of movement and motor coordination, depression, anxiety and social isolation ${ }^{(3-4)}$. Because lymphedema is caused by lymphatic dysfunction that leads to abnormal accumulation of interstitial fluid containing high molecular weight proteins, radiotherapy increases the risk of lymphedema due to the possibility of worsening lymphatic obstruction ${ }^{(5)}$.

The prevalence of lymphedema worldwide is unknown. The prevalence rate of lymphedema secondary to breast cancer varies from 5 to $60.0 \% \%^{(6-7)}$.

In recent years, radical mastectomy has been replaced by more conservative techniques and axillary emptying by sentinel lymph node biopsy for tumors in the early stages, resulting in improved survival with fewer associated complications ${ }^{(8)}$.

Prevention of lymphedema encompasses the woman's knowledge about this sequel. Obtaining information about lymphedema combined with the practice of behaviors can reduce its occurrence ${ }^{(9)}$. Regarding the clinical practice of nurses, it is their competence to prevent and rehabilitate morbidities related to cancer therapy, preventing complications, relieving symptoms, and promoting quality of life $\mathrm{e}^{(10)}$.

Lymphedema control includes women's knowledge to adhere to protective measures with healthy living practices, compression clothing and weight control(11). Studies evaluating women's knowledge about the prevalence of lymphedema and the knowledge of women may provide subsidies for changing clinical practice $^{(12)}$.

Thus, this study aimed to estimate the prevalence and to identify possible factors associated with the occurrence of lymphedema in women undergoing treatment for breast cancer.

\section{Methods}

This is a prevalence study, developed at the outpatient clinic, belonging to the Brazilian Health System, of a large hospital in Belo Horizonte, MG, Brazil. The sample of 125 women was obtained by simple random probabilistic sampling. The sample calculation considered the prevalence of $10.0 \%$, reliability of $95.0 \%$ and an error of $5.0 \%{ }^{(6)}$. Inclusion criteria were: female gender and having undergone surgical treatment for breast cancer for at least six months. Case was considered women with diagnosis of lymphedema performed by the physician and recorded in medical records.

Data were collected from January to March 2012, through individual interviews using a semi-structured questionnaire and consultation in the medical record with a collection instrument that contained sociodemographic and clinical data of the patients. Both instruments were developed by the researcher.

The presence or absence of lymphedema was considered as a response variable. The following variables were analyzed as possibly associated with the occurrence of lymphedema: age (in years), marital status (married, single, divorced/widowed), educatio- 
nal level (less than 4 years, between 5 and 8 years and more than 9 years of study), family income (less than a minimum wage, between 1 and 3 minimum wages and more than 3 minimum wages), body mass index (normal, overweight and obesity), sentinel lymph node biopsy (yes and no), axillary lymphadenectomy (yes and no), surgical approach (total mastectomy, partial mastectomy and lumpectomy), breast reconstruction (yes and no), complementary treatment (chemotherapy and radiotherapy), treatment complications (yes, no and which), level of knowledge about lymphedema (high, low and average), having received information about how to prevent lymphedema (yes and no).

The prevalence of lymphedema was calculated for the study period. Descriptive analysis of the data included simple frequency, central tendency measures (mean and median) and measures of variability (standard deviation).

Bivariate and multivariate analyzes were performed using logistic regression. Variables that presented a p-value lower than 0.25 were selected for the multivariate logistic model. In the multivariate analysis, the selected variables were withdrawn one by one by the stepwise backward method, considering p-value less than 0.05, Hosmer-Lemeshow test and Nagelkerke pseudo $\mathrm{R}^{2}$, indicating the contribution of the variable to better fit the model.

The study complied with the formal requirements contained in the national and international regulatory standards for research involving human beings.

\section{Results}

The mean age of the 125 study participants was 54.4 years $( \pm 10.5)$. Predominantly, women were married $(72 ; 57.6 \%)$, had schooling up to four years of study $(77 ; 61.6 \%)$, and family income from one to three minimum wages $(64 ; 51.2 \%)$.
More than half of the women $(65 ; 52.8 \%)$ performed sentinel lymph node biopsy and the axillary lymph nodes were removed in 114 (91.2\%) patients. Radical mastectomy was performed in 96 (77.4\%) women, radiotherapy in $80(64.0 \%)$ and chemotherapy in $120(96.0 \%)$, and $91(72.8 \%)$ presented some complications related to treatment, such as retraction of the operative wound, seroma and infection.

Of the 125 women, 43 (34.4\%) developed lymphedema, with medical diagnosis recorded in medical records. It was observed in this study that the mean age of these women with breast cancer who developed lymphedema was 53.5 years; \pm 10.3 .

During the study period, among the 125 mastectomized women, 43 had lymphedema; so, the prevalence in the period was $34.4 \%$.

Bivariate analysis showed an association of the majority of covariates with the variable lymphedema response $(\mathrm{p}<0.25)$, as presented in Table 1. Variables related to the clinical characteristics of participants who had lymphedema (body mass index, sentinel lymph node, total mastectomy, lumpectomy, radiotherapy and chemotherapy, and the presence of treatment complications) were taken for multivariate analysis. The chemotherapy variable, which presented zero in one of the cells was not taken to the multivariate model.

Table 2 presents the final logistic model. The variables total mastectomy and lumpectomy did not remain in the final model of multivariate analysis.

There was a statistically significant difference $(p=0.013)$ regarding the occurrence of lymphedema among patients who had normal weight and patients who were obese. Patients who were obese had a chance of having lymphedema 3.79 [1.32; 10.88] times greater than patients who had normal weight. There was no significant difference $(p=0.241)$ between patients who had normal weight and patients who were overweight. 
Table 1 - Bivariate analysis of co-variables in relation to the occurrence of lymphedema

\begin{tabular}{|c|c|c|c|c|c|}
\hline \multirow{3}{*}{ Variable } & \multicolumn{3}{|c|}{ Lymphedema } & \multirow{3}{*}{ CI $(95 \%)^{*}$} & \multirow{3}{*}{$\mathbf{p}$} \\
\hline & \multirow{2}{*}{$\begin{array}{c}\text { No }(n=82) \\
n(\%)\end{array}$} & \multirow{2}{*}{$\begin{array}{c}\text { Yes }(n=43) \\
n(\%)\end{array}$} & \multirow{2}{*}{$\begin{array}{l}\text { Odds } \\
\text { Ratio }\end{array}$} & & \\
\hline & & & & & \\
\hline \multicolumn{6}{|l|}{ Body mass index } \\
\hline Normal & $35(77.8)$ & $10(22.2)$ & 1 & - & \\
\hline Obese & $20(52.6)$ & $18(47.4)$ & 3.15 & {$[1.22 ; 8.13]$} & 0.054 \\
\hline Overweight & $27(64.3)$ & $15(35.7)$ & 1.94 & & \\
\hline \multicolumn{6}{|c|}{ Sentinel lymph node biopsy } \\
\hline No & $46(76.7)$ & $14(23.3)$ & 1 & & \multirow{2}{*}{0.012} \\
\hline Yes & $36(55.4)$ & $29(44.6)$ & 2.65 & {$[1.22 ; 5.73]$} & \\
\hline \multicolumn{6}{|c|}{$\begin{array}{l}\text { Removed axillar lymph } \\
\text { node }\end{array}$} \\
\hline No & $9(81.8)$ & $2(18.2)$ & 1 & - & \multirow{2}{*}{0.328} \\
\hline Yes & $73(64.0)$ & $41(36.0)$ & 1.66 & {$[0.51 ; 9.09]$} & \\
\hline \multicolumn{6}{|c|}{ Lymph nodes removed } \\
\hline Median (mix. max.) & $16(0-40)$ & $15(0-33)$ & - & - & 0.793 \\
\hline \multicolumn{6}{|c|}{ Positive lymph nodes removed } \\
\hline Median (mix. max.) & $2(0-13)$ & $2(0-15)$ & - & - & 0.753 \\
\hline \multicolumn{6}{|l|}{ Total mastectomy } \\
\hline No & $16(55.2)$ & $13(44.8)$ & 1 & - & \multirow{2}{*}{0.177} \\
\hline Yes & $66(68.8)$ & $30(31.2)$ & 0.56 & {$[0.24 ; 1.31]$} & \\
\hline \multicolumn{6}{|l|}{ Partial mastectomy } \\
\hline No & $70(67.3)$ & 34 (32.7) & 1 & - & \multirow{2}{*}{0.371} \\
\hline Yes & $12(57.1)$ & $9(42.9)$ & 1.54 & {$[0.59 ; 4.02]$} & \\
\hline \multicolumn{6}{|l|}{ Lumpectomy } \\
\hline No & $79(66.9)$ & 39 (33.1) & 1 & - & \multirow{2}{*}{0.231} \\
\hline Yes & $3(42.9)$ & $4(57.1)$ & 1.98 & {$[0.61 ; 11.01]$} & \\
\hline \multicolumn{6}{|l|}{ Reconstruction } \\
\hline No & $68(64.2)$ & $38(35.8)$ & 1 & - & \multirow{2}{*}{0.421} \\
\hline Yes & $14(73.7)$ & $5(26.3)$ & 0.64 & {$[0.21 ; 1.91]$} & \\
\hline \multicolumn{6}{|l|}{ Radiotherapy } \\
\hline No & 35 (77.8) & $10(22.2)$ & 1 & - & \multirow{2}{*}{0.032} \\
\hline Yes & $47(58.8)$ & $33(41.2)$ & 2.46 & {$[1.07 ; 5.65]$} & \\
\hline \multicolumn{6}{|l|}{ Chemotherapy } \\
\hline No & $5(100.0)$ & - & 1 & - & 161 \\
\hline Yes & $77(64.2)$ & $43(35.8)$ & 2.76 & {$[0.33 ; 114.34]$} & 0.104 \\
\hline Treatment complica & & & & & \\
\hline No & $26(76.5)$ & $8(23.5)$ & 1 & - & 0110 \\
\hline Yes & $56(61.5)$ & $35(38.5)$ & 2.03 & {$[0.83 ; 4.99]$} & \\
\hline Knowledge level & & & & & \\
\hline High & $8(57.1)$ & $6(42.9)$ & 1 & - & \\
\hline Low & $26(76.5)$ & $8(23.5)$ & 0.41 & {$[0.11 ; 1.54]$} & 0.261 \\
\hline Average & 47 (61.8) & $29(38.2)$ & 0.82 & {$[0.26 ; 2.61]$} & \\
\hline
\end{tabular}

Table 2 - Final logistic regression model of co-variables in relation to the occurrence of lymphedema

\begin{tabular}{lccc}
\hline \multirow{2}{*}{ Source } & \multicolumn{3}{c}{ Final Model } \\
\cline { 2 - 4 } & $\begin{array}{l}\text { Odds } \\
\text { Ratio }\end{array}$ & CI (95\%) & p \\
\hline Body Mass Index = Normal & & & \\
Body Mass Index = Obese & 3.79 & {$[1.32 ; 10.88]$} & 0.013 \\
Body Mass Index = Overweight & 1.86 & {$[0.66 ; 5.23]$} & 0.241 \\
Sentinel lymph node biopsy = No & & & \\
Sentinel lymph node biopsy = Yes & 4.08 & {$[1.69 ; 9.82]$} & 0.002 \\
Radiotherapy = No & & & \\
Radiotherapy = Yes & 2.89 & {$[1.16 ; 7.20]$} & 0.023 \\
Treatment complications = No & & & \\
Treatment complications = yes & 2.77 & {$[1.03 ; 7.40]$} & 0.043 \\
Pseudo R ${ }^{2}$ (Negelkerke) & & $23.8 \%$ & \\
Hosmer-Lemeshow test (p-value) & & 0.322 & \\
\hline${ }^{*}$ Confidence interval & & &
\end{tabular}

There was a significant influence $(p=0.002)$ of sentinel lymph node biopsy on lymphedema, and patients who had undergone biopsy had a chance of having lymphedema 4.08 [1.69; 9.82] times greater than those who had not undergone biopsy.

There was also significant $(p=0.023)$ influence of radiotherapy on lymphedema, and patients who had undergone radiotherapy had a chance of having lymphedema $2.89[1.16 ; 7.20]$ times greater than those who had not undergone radiotherapy.

Complications related to the treatment of breast cancer were described in the medical records of $35(81.4 \%)$ of the women with lymphedema. The most frequent complications were: retraction, paresthesia, adhesion, seroma and fibrosis. There was a significant influence $(\mathrm{p}=0.043)$ on the occurrence of treatment complications on lymphedema, and patients who had complications had a chance of having lymphedema 2.77 [1.03; 7.40] times greater than patients who had no complications.

Body mass index, sentinel node biopsy, radiotherapy and treatment complications were able to explain $23.8 \%$ of the occurrence of lymphedema.

Through the Hosmer-Lemeshow test, the final 
model with the variables body mass index, sentinel lymph node biopsy, radiotherapy and treatment complication presented a good adjustment $(\mathrm{p}=0.322)$.

\section{Discussion}

Sectional studies have methodological limitations as they do not separate cause and effect. In this study, we used simple random sampling, which increases internal validity and external validity, making possible to extrapolate the results. Despite the limitations of this method as the impossibility of establishing a cause-and-effect relationship, prevalence studies are important for understanding the problem. No published studies were found evaluating the prevalence of lymphedema in women who survived breast cancer in Minas Gerais.

Breast cancer is the most frequent among women in Brazil and in the world, and the most affected women are those over 50 years old. This fact can be explained by oncogenetic characteristics that accumulate throughout life. Age over 50 years is in agreement with this study ${ }^{(11-14)}$.

Knowing the level of education of women surviving breast cancer is relevant to lymphedema prevention actions ${ }^{(13)}$. Although most of the participants in this study had four or less years of study, no statistical significance was found between schooling and lymphedema.

No studies were found associating family income and the occurrence of lymphedema. Lymphedema is a morbidity that can lead to physical, functional, psychological and social limitations, generating a great impact on the quality of life of these women ${ }^{(11-15)}$. This study found a significant relationship between women with family income between one and three minimum wages and the development of lymphedema.

Prevalence of lymphedema varies widely in the literature, from $6.0 \%$ to $49.0 \%$, depending on the criteria adopted for the measurement and definition of lymphedema, the time elapsed from surgery until evaluation and the characteristics of the studied population. Different methodologies may also have an impact on the results ${ }^{(16)}$. Knowledge on the risk factors for developing lymphedema is important for the planning and execution of preventive behaviors during all the perioperative stages ${ }^{(13)}$. In this study, the prevalence was high and may even be underestimated, since only those reported in medical records were considered cases of lymphedema. In this sense, only women with more advanced or symptomatic lymphedema may have been included, since the evaluation did not follow standardized behavior ${ }^{(6)}$.

Regarding body mass index, 33 (76.7\%) of the women with lymphedema had a body mass index $>25$ (34.9\% were overweight and $41.9 \%$ were obese). There was a significant difference $(p=0.013)$ in the occurrence of lymphedema between patients with normal body mass index and obese patients, in which obese patients presented 3.79 times greater chance of having lymphedema. Authors consider increased body weight a risk factor for lymphedema, although the biological mechanism of this relationship is still

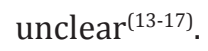

Sentinel lymph node biopsy is a noninvasive technique and is a potential alternative to avoid axillary lymphadenectomy. Researches have shown that lymphedema is less incident in women undergoing sentinel lymph node biopsy than in those who underwent radical lymphadenectomy. Several morbidities are related to the non-performance of sentinel lymph node biopsy, including seroma, sensorial disorders and lymphedema, reduction of arm movement, weakness of the ipsilateral limb to the treated breast and pain $^{(18-20)}$.

In the present study, women submitted to sentinel lymph node biopsy, who had positive lymph node, also underwent lymphadenectomy and radiotherapy. Only one woman was submitted to lymph node biopsy alone and she had no diagnosis of lymphedema until the date of the interview. No statistically significant relationship was found for axillary lymphadenectomy $(\mathrm{p}=0.32)$, number of lymph nodes removed $(\mathrm{p}=0.79)$, and positivity of lymph nodes removed $(\mathrm{p}=0.75)$ with 
lymphedema. In the group of patients diagnosed with lymphedema, 41 (95.3\%) women had undergone lymphadenectomy, had an average of 15 lymph nodes removed and, on average, four lymph nodes were positive. Lymphadenectomy is a risk factor of great importance for the development of lymphedema, according to literature ${ }^{(4-14)}$. However, in view of the obtained results, it is understood that the compensatory mechanisms that occur after axillary lymphadenectomy and also individual factors involving the studied women may have interfered in the results.

In view of the findings, the following associated factors were evaluated: sentinel lymph node biopsy, axillary lymphadenectomy and radiotherapy. Only 20 (16.0\%) women had been submitted to one of these factors, and of these, only two (12.5\%) women had developed lymphedema, both of whom had undergone axillary lymphadenectomy. Of the total sample, 105 $(84.0 \%)$ had been submitted to at least two of these risk factors, and 41 (48.8\%) had developed lymphedema. In agreement with the literature, it is understood that the etiology and risk factors for the development of lymphedema in patients submitted to surgery for breast cancer appear to be multifactorial and not yet fully understood ${ }^{(17)}$.

Previous study showed that the type of surgery performed and breast reconstruction is not associated with lymphedema. In this study, no significant relationship was found between type of total mastectomy surgery $(\mathrm{p}=0.17)$; partial mastectomy $(\mathrm{p}=0.37)$; lumpectomy $(\mathrm{p}=0.23)$ and breast reconstruction $(p=0.42)$ and the occurrence of lymphedema ${ }^{(13)}$.

Regarding radiotherapy, literature is unanimous in stating that it is a risk factor for lymphede$\mathrm{ma}^{(14-17)}$. In the present study, 33 (76.7\%) women with lymphedema and 47 (57.3\%) of the women without lymphedema diagnosis had been submitted to radiotherapy. Submission to radiotherapy increased by 2.89 times the woman's chance of developing lymphedema ( $\mathrm{p}=0.023)$.

According to the literature, no relation was found between performing chemotherapy and the development of lymphedema, odds ratio $(p=0.16)(0.33$ $114.34)^{(13)}$.

The present study found a statistically significant association between the occurrence of lymphedema and the presence of treatment-related complication for breast cancer ( $\mathrm{p}=0.043)$. Having some type of complication increases 2.77 times the chance of developing lymphedema. A prevalence study evaluating complications related to surgical treatment found seroma, early edema and infection as the most frequent complications, corroborating with the findings in this study ${ }^{(6)}$.

In this study, women's level of knowledge about lymphedema was evaluated and this variable did not present a statistically significant relationship between lymphedema and its appearance $(\mathrm{p}=0.26)$. According to a study conducted at a teaching hospital in New York, providing information on how to prevent lymphedema is a protective factor ${ }^{(12)}$.

Nursing professionals should propose care programs with adequate guidelines for these patients, regarding care with the upper limb homolateral to the surgery, with the surgical site, aspiration drainage, protection of the exposed area during radiotherapy, exercising with the arm, assessment and diagnosis of signs of edema, in addition to providing emotional support and rehabilitation services ${ }^{(15-16)}$.

Risk factors for the development of lymphedema in patients submitted to breast cancer surgery are not yet fully understood in the literature, since there is a lack of research in the area, as this is the first study on the theme conducted in the state of Minas Gerais, Brazil.

This study is important to support the clinical practice of professionals in the care provided to breast cancer survivors, considering that this is a chronic, high prevalence and disabling morbidity. Thus, health practitioners must have theoretical and clinical subsidies both to document the problem and to raise awareness about the relevance of lymphedema to 
women in relation to their position in society, family and individual. In this way, this study brings practical-applicability tools regarding the identification of associated factors and the high prevalence of lymphedema in survivors of oncological treatment.

\section{Conclusion}

The prevalence of lymphedema in this study was high. The variables positively related to lymphedema, considered as associated factors, were: obesity, sentinel lymph node biopsy, radiotherapy and some treatment complications (adhesion, retraction, paraesthesia, seroma, fibrosis, infection and dehiscence).

\section{Collaborations}

Bonisson PLV, Fu MR, Matos SS, Simino GPR, Lima ERP and Ercole FF contributed to the design, analysis and interpretation of the data, essay writing, critical review of content and approval of the final version to be published.

\section{References}

1. Ministério da Saúde (BR). Instituto Nacional de Câncer José Alencar Gomes da Silva. Coordenação de Prevenção e Vigilância. Estimativa 2016: incidência de câncer no Brasil. Rio de Janeiro: Ministério da Saúde; 2015.

2. Iyeyasu H. Câncer de mama. In: Lopes A, Chammas $\mathrm{R}$, Iyeyasu $\mathrm{H}$, organizadores. Oncologia para a graduação. São Paulo: Lemar; 2013. p.401-7.

3. Oliveira MMF, Amaral MTP, Gurgel MSC. Lymphatic compensation during the postoperative period after breast cancer treatment with axillary dissection. J Vasc Bras. 2015; 14(2):161-7.

4. Motomura K. Sentinel node biopsy for breast cancer: past, present, and future. Breast Cancer. 2015; 22(3):212-20.
5. Paskett ED. Symptoms: lymphedema. Adv Exp Med Biol. 2015; 862:101-13. doi: 10.1007/978-3319-16366-6_8

6. Bergmann A, Mattos IE, Koifman RJ. Incidência e prevalência de linfedema após tratamento cirúrgico do câncer de mama: revisão de literature. Rev Bras Cancerol. 2007; 53(4):461-70.

7. Fu MR, Lasinski BB. Lymphedema management. In: Ferrell BF, Coyle N, Paice J, organizadores. Oxford textbook of palliative nursing. Oxford University Press: New York; 2014. p.279-96.

8. Chong C, Walters D, Silva P, Taylor C, Spillane A, Kollias J, et al. Initial axillary surgery: results from the breast surg ANZ quality audit. ANZ J Surg. 2015; 85(10):777-82.

9. Krzywonos A, Ochałek K, Krzywonos-Zawadzka A, Pitala K. Assessment of knowledge of cancer and lymphoedema among breast cancer survivors. Prz Menopauzalny 2014; 13(5):273-9.

10. Prandi C, Garrino L, Clerico M, Sommovigo T, Vellone E, Alvaro R. Therapeutic Education to cancer patients: experiences of Italian nurses. Prof Inferm. 2014; 67(4):243-51.

11. Fu MR. Breast cancer-related lymphedema: symptoms, diagnosis, risk reduction, and management. World J Clin Oncol. 2014; 5(3):241-7.

12. Fu MR, Chen, CM, Haber J, Guth AA, Axelrod D. The effect of providing information about lymphedema on the cognitive and symptom outcomes of breast cancer survivors. Ann Surg Oncol. 2010; 17(7):1847-53.

13. Rebegea L, Firescu D, DumitruM, Anghel R. The incidence and risk factors for occurrence of arm lymphedema after treatment of breast cancer. Chirurgia (Bucur). 2015; 110(1):33-7.

14. Toyserkani NM, Jørgensen MG, Haugaard K, Sørensen JA. Seroma indicates increased risk of lymphedema following breast cancer treatment: a retrospective cohort study. Breast. 2017; 24(32):102-4.

15. Fu MR, Deng J, Armer JM. Putting evidence into practice: cancer related lymphedema. Clin J Onco Nurs. 2014; 18(supl):68-79. 
16. Paiva DMF, Rodrigues VO, Cesca MG, Palma PV, Leite ICG. Prevalence of lymphedema in women undergoing treatment for breast cancer in a referral center in south eastern Brazil. BMC Womens Health. 2013; 13(6):13-6.

17. Ugur S, Arıcı C, Yaprak M, Mescı A, Arıcı GA, Dolay K. Risk factors of breast cancer-related lymphedema. Lymphat Res Biol. 2013; 11(2):72-5.

18. El Hage $\mathrm{CH}$, Headon $\mathrm{H}$, Wazir U, Abtar H, Kasem A, Mokbel K. Is sentinel lymph node biopsy indicated in patients with a diagnosis of ductal carcinoma in situ? A systematic literature review and meta-analysis. Am J Surg. 2017; 213(1):171-80.
19. Alsaif AA. Sentinel lymph node biopsy in breast cancer. Saudi Med J. 2015; 36(9):1053-60.

20. Manca G, Rubello D, Tardelli E, Giammarile F, Mazzarri S, Boni G, et al. Sentinel lymph node biopsy in breast cancer: indications, contraindications, and controversies. Clin Nucl Med. 2015; 41(2):126-33. 